\title{
Risk Factors for Post-Endoscopic Retrograde Pancreatography Pancreatitis: A Retrospective Chart Review in a Regional Hospital in Japan
}

\author{
Takuya Shimamura a, b Koichi Miyahara ${ }^{a}$ Ayako Takamoric Hidenori Hidaka ${ }^{a}$ \\ Yoichiro Ito $^{a}$ Shun Fujimoto $^{a}$ Hironobu Takedomi ${ }^{b}$ Nanae Tsuruoka ${ }^{b}$ \\ Yasuhisa Sakata $^{b}$ Yuichiro Eguchi ${ }^{b}$ Koichi Node ${ }^{b}$ Takahiro Noda $^{a}$ \\ Kazuma Fujimoto ${ }^{\text {b, }}$ d \\ anternal Medicine, Karatsu Red Cross Hospital, Saga, Japan; ${ }^{b}$ Department of Internal Medicine, Saga Medical \\ School, Saga, Japan; ' Division of Clinical Research Center, Saga University Hospital, Saga, Japan; ${ }^{d}$ International \\ University of Health and Welfare Graduate School, Fukuoka, Japan
}

\section{Keywords}

Adverse event - Emergency · Off hours - Cholangiography · Pancreatography

\section{Abstract \\ Background: Endoscopic retrograde pancreatography (ERCP) is sometimes complicated by post-ERCP pancreatitis (PEP), which is a severe adverse effect. Objective: The pres- ent study was performed to (i) evaluate the risk factors for PEP and (ii) compare the risk of PEP after ERCP performed in the off hours versus regular hours. Methods: This retrospec- tive study included 374 patients who underwent ERCP from January 2013 to December 2017. Among these patients, 38 (10.2\%) developed PEP. The potential risk factors for PEP were evaluated by multivariate regression analysis, and the risk of PEP was compared between ERCP performed during regular hours and off hours. Results: The independent risk factors for PEP were a relatively younger age $(<75$ years; $p=$ $0.024)$, female sex $(p=0.002)$, a history of pancreatitis $(p=$ $0.044)$, and performance of pancreatography $(p=0.010)$. Use of a diclofenac suppository and performance of pancreatic stenting were not preventive for PEP after ERCP. The compli-}

cation rate of PEP did not differ between ERCP performed during the off hours versus regular hours. Conclusions: A relatively younger age ( $<75$ years), female sex, a history of pancreatitis, and performance of pancreatography were potential risk factors for PEP, whereas the risk of PEP was not different between ERCP performed during the off hours versus regular hours.

(c) 2019 S. Karger AG, Basel

\section{Introduction}

Endoscopic retrograde pancreatography (ERCP) plays an important role in the diagnosis and treatment of pancreatic and biliary system disorders [1-4]. Post-ERCP pancreatitis (PEP) is one of the most serious complications of ERCP. In recent years, computed tomography and/or magnetic resonance cholangiopancreatography (MRCP) have become more highly applicable diagnostic approaches for pancreatic and biliary system diseases than ERCP [5-9].

The risk factors for PEP are indicated in both international and Japanese medical practice guidelines [10-15]. The patient-related risk factors of PEP include female sex, karger@karger.com

www.karger.com/dig

(C) 2019 S. Karger AG, Base

Karger"
Koichi Miyahara, MD, $\mathrm{PhD}$

Internal Medicine, Karatsu Red Cross Hospital

Watada 2430, Karatsu-shi

Saga 847-8588 (Japan)

E-Mail mwgbn398@yahoo.co.jp 
a history of pancreatitis, a history of PEP, sphincter of Oddi dysfunction, and intraductal papillary mucinous neoplasm, and the technical-related risk factors for PEP include difficult cannulation, endoscopic sphincterotomy, precut sphincterotomy, and pancreatography [1015]. Although PEP has a very guarded prognosis and may be fatal in some cases, most previous studies were performed in high-volume centers [16, 17]. Although these risk factors are consistently reported in the medical guidelines and references, complete prevention of PEP has not been achieved because of the possible presence of other underlying risk factors for PEP [18-21].

Several reports have indicated that the risk of adverse events is higher when several endoscopic therapies, including emergency endoscopic hemostasis, are performed in the off hours than during regular hours [22, 23]. Although the risk associated with emergency offhours ERCP was not clearly evaluated, emergency ERCP appears to be effective for several diseases, including acute cholangitis. The present retrospective chart review was performed to (i) evaluate the risk factors for PEP in a regional hospital in Japan and (ii) determine whether the risk of PEP is higher after ERCP performed during off hours than regular hours.

\section{Materials and Methods}

This retrospective single-center study was conducted at the Karatsu Red Cross Hospital (Karatsu, Saga, Japan) and included all patients who underwent ERCP from January 2013 to December 2017. A total of 1,094 patients underwent ERCP, and 717 were excluded from the study because they had a history of previous ERCP treatment. Another 3 patients were excluded due to the lack of a serum amylase concentration in the medical records. Finally, 374 patients who had undergone ERCP were analyzed in the study.

ERCP was conducted after the induction of analgesia and sedation by intravenous diazepam and pentazocine. All ERCP procedures were performed by several expert endoscopists with $\geq 10$ years of experience and trainees with $<10$ years of experience. All evaluated patients underwent their first ERCP procedure and had no history of endoscopic sphincterotomy, papillary balloon dilatation, or bile or pancreatic duct stenting. PEP was diagnosed based on new-onset abdominal pain lasting $>24 \mathrm{~h}$ after ERCP with an increased serum amylase level of $>3$ times the upper limit of normal, which was defined by Cotton's criteria [24].

The patients' electronic medical records were used to record age, sex, height, weight, indication for ERCP, history of pancreatitis, and a diverticulum near the papilla of Vater. Whether the patient had undergone pancreatography, the administration of a diclofenac suppository, or pancreatic stenting; the ERCP examination period; the ERCP starting time with respect to arrival at the hospital; and whether MRCP was performed before ERCP were also recorded. In terms of the start of ERCP and arrival time of the patient, the regular hours were defined as 08:30-17:00 on week- days; and off hours were defined as 17:00-8:30 on weekdays or anytime on weekends/holidays.

For the statistical analysis, the chi-square test or $t$ test was performed to identify differences in patient characteristics between the 2 groups. A univariate analysis was performed to identify the relevance of several factors analyzed in this study. Two multiple logistic regression models were considered to evaluate the relationships of the evaluated factors with the risk of PEP. The full model was adjusted by all confounding factors (Model 1), and the stepwise model was performed using a stepwise selection method with the same entry and removal significance level of 0.2 (Model 2 ). Before considering the multivariate analysis, correlation was confirmed between each of the factors that had a reduced correlation rate. The performance of MRCP before ERCP (yes/no) and administration of a diclofenac suppository (yes/no) were considered in the model 2 as necessarily stay variables. The statistical measures used in reporting associations were the OR and 95\% CI. All $p$ values were two sided; those of $<0.05$ indicated statistical significance. All analyses were performed with JMP version 13.2.1 (SAS Institute Inc., Cary, NC, USA).

\section{Results}

The potential risk factors for PEP are shown in Table 1. PEP occurred in $38(10.2 \%)$ of the 374 ERCP procedures, which was diagnosed by CT and/or US using the Cotton's criteria [24], which met the guidelines for the management of acute pancreatitis: JPN guidelines 2015 [25]. One patient complicated severe pancreatitis in the Cotton's criteria. The mean age of all the 374 patients was $72.3 \pm 13.9$ years. PEP more often occurred in younger patients aged $<75$ years $(65.8 \%)$ than in older patients aged $>75$ years $(34.2 \%)$. In terms of sex, women were at higher risk of PEP than men (71.1 vs. $29.0 \%$, respectively). Other patient-related factors including the indication for ERCP, body mass index, history of pancreatitis, a diverticulum near the papilla of Vater, and clinical symptoms were not risk factors for PEP. Among intraoperative ERCP-related factors, only performance of pancreatography was a risk factor for PEP, as it occurred in $81.6 \%(31 / 38)$ of patients; the purpose of ERCP (treatment or observation), administration of a diclofenac suppository, performance of pancreatic stenting, and the procedure period of ERCP were not risk factors for PEP. Neither off-hours ERCP nor regular hours ERCP were a risk factor for PEP.

The results of the univariate analysis are shown in Table 2. These data indicate that female sex and performance of pancreatography were risk factors for PEP. The results of the multivariate analysis are shown in Table 3. All factors evaluated in the present study were evaluated in the multivariate analysis because all were independent of one another with no significant correlation, as shown in Table 
4. The multivariate analysis indicated that the risk factors for PEP were an age of $<75$ years $(p=0.024)$, female sex $(p=0.002)$, a history of pancreatitis $(p=0.044)$, and pancreatography $(p=0.010)$. Neither the start time of ERCP (regular hours or off hours) nor the arrival time of the patient was a risk factor for PEP after ERCP.

\section{Discussion}

The present retrospective chart review in a regional single hospital indicated that (i) the risk factors for PEP were a younger age, female sex, performance of pancreatography, and a history of pancreatitis and (ii) the incidence of PEP were not different between regular hours and off hours. The complication rate of PEP in the present study of the patients without the previous ERCP was $10.2 \%$, which is similar to previous reports (3-15\% among ERCP procedures) $[5,13,14,19]$. The present study evaluated 8 factors using a multivariate analysis: 6 factors selected by the stepwise method (age, sex, body mass index, history of pancreatitis, diagnostic or therapeutic ERCP, and pancreatography) and 2 essential factors (administration of diclofenac suppository and performance of MRCP before ERCP). As a result, 4 factors were identified as risk factors for PEP: age, sex, pancreatography, and a history of pancreatitis.

Why a younger age was a risk factor for PEP in the present study remains unclear. Another study indicated that age was not related to PEP [14]. The exocrine function of the pancreas decreases with aging [26-28], which might help to explain why the incidence of PEP was dependent upon age. The fact that female sex was a risk factor for PEP might be due to the high prevalence of both cholelithiasis and sphincter of Oddi dysfunction [10-14, 29-31]. Several studies have shown that pancreatography directly increases the pressure of the pancreatic duct [3234], and a history of pancreatitis are risk factors for PEP $[10,11,14]$. These findings are consistent with those of the present study.

Several previous studies have indicated that the use of low-dose rectal diclofenac $[19,35-38]$ and the performance of pancreatic stenting $[39,40]$ effectively prevent PEP. The present study did not demonstrate the preventive effect of diclofenac and pancreatic stenting; however, the dose of diclofenac (50 mg, which might not have been enough for the prevention of PEP) and the performance of pancreatic stenting in the present study were limited only to patients who underwent several cannulations during the procedure.

The complication rate of PEP was not different between ERCP performed during regular hours and off
Table 1. Potential risk factors for post-ERCP pancreatitis

\begin{tabular}{|c|c|c|c|}
\hline Variables & PEP & Non-PEP & $p$ value \\
\hline \multicolumn{4}{|c|}{ Patient-related factors } \\
\hline \multicolumn{4}{|c|}{ Age, years } \\
\hline$\geq 75$ & $13(34.2)$ & $171(50.9)$ & \multirow[t]{2}{*}{$0.049^{*}$} \\
\hline$<75$ & $25(65.8)$ & $165(49.1)$ & \\
\hline \multicolumn{4}{|l|}{ Gender } \\
\hline Female & $27(71.1)$ & $139(41.4)$ & \multirow[t]{2}{*}{$0.001^{*}$} \\
\hline Male & $11(29.0)$ & $197(58.6)$ & \\
\hline \multicolumn{4}{|l|}{ Indications } \\
\hline No cancer & $28(73.7)$ & $253(75.3)$ & \multirow[t]{2}{*}{0.828} \\
\hline Cancer & $10(26.3)$ & $83(24.7)$ & \\
\hline \multicolumn{4}{|l|}{ BMI } \\
\hline$\leq 19$ & $12(33.3)$ & $66(19.9)$ & \multirow[t]{2}{*}{0.074} \\
\hline$>19$ & $24(66.7)$ & $266(80.1)$ & \\
\hline \multicolumn{4}{|c|}{ History of pancreatitis } \\
\hline Yes & $3(7.9)$ & $14(4.2)$ & \multirow[t]{2}{*}{0.336} \\
\hline No & $35(92.1)$ & $322(95.8)$ & \\
\hline \multicolumn{4}{|l|}{ Diverticulum } \\
\hline Yes & $9(23.7)$ & $75(22.3)$ & \multirow[t]{2}{*}{0.850} \\
\hline No & $29(76.3)$ & $261(77.7)$ & \\
\hline \multicolumn{4}{|c|}{ Symptoms of the arrival time } \\
\hline Yes & $17(44.7)$ & $188(56.0)$ & \multirow[t]{2}{*}{0.189} \\
\hline No & $21(55.3)$ & $148(44.1)$ & \\
\hline \multicolumn{4}{|c|}{ ERCP related factors } \\
\hline \multicolumn{4}{|c|}{ Purpose of ERCP } \\
\hline Treatment & $35(92.1)$ & $287(85.4)$ & \multirow[t]{2}{*}{0.228} \\
\hline Observation & $3(7.9)$ & $49(14.6)$ & \\
\hline \multicolumn{4}{|l|}{ Pancreatography } \\
\hline Yes & $31(81.6)$ & $199(59.2)$ & \multirow[t]{2}{*}{$0.005^{*}$} \\
\hline No & $7(18.4)$ & $137(40.8)$ & \\
\hline \multicolumn{4}{|c|}{ Diclofenac suppository } \\
\hline Yes & $18(47.4)$ & $156(46.4)$ & \multirow[t]{2}{*}{0.912} \\
\hline No & $20(52.6)$ & $180(53.6)$ & \\
\hline \multicolumn{4}{|l|}{ Pancreatic stenting } \\
\hline Yes & $8(21.1)$ & $48(14.3)$ & 0.288 \\
\hline No & $30(79.0)$ & $288(85.7)$ & \\
\hline Time required for & & & \\
\hline$\geq 1 \mathrm{~h}$ & $7(18.4)$ & $31(9.2)$ & 0.102 \\
\hline$<1 \mathrm{~h}$ & $31(81.6)$ & $305(81.9)$ & \\
\hline Start time of ERC & & & \\
\hline Off hours & $20(52.6)$ & $155(46.1)$ & 0.447 \\
\hline Regular hours & $18(47.4)$ & $181(53.9)$ & \\
\hline Arrival time of the & & & \\
\hline Off hours & $7(18.4)$ & $61(18.2)$ & 0.968 \\
\hline Regular hours & $31(81.6)$ & $275(81.9)$ & \\
\hline MRCP before ERC & & & \\
\hline Yes & $20(52.6)$ & $172(51.2)$ & 0.866 \\
\hline No & $18(47.4)$ & $164(48.4)$ & \\
\hline
\end{tabular}

Data are presented as $n(\%)$

$* p<0.05$

ERCP, endoscopic retrograde cholangiopancreatography; $\mathrm{PEP}$, post-ERCP pancreatitis; BMI, body mass index; MRCP, magnetic resonance cholangiopancreatography. 
Table 2. Unadjusted ORs for PEP by univariate analysis

\begin{tabular}{llll}
\hline Factors & Unadjusted OR & $95 \%$ CI & $p$ value \\
\hline Age, years $(<75 / \geq 75)$ & 1.99 & $0.99-4.03$ & 0.055 \\
Gender, female/male & 3.48 & $1.67-7.25$ & $0.001^{*}$ \\
Indications (no cancer/cancer) & 0.92 & $0.43-1.97$ & 0.827 \\
BMI ( $\leq 19 />19)$ & 2.02 & $0.96-4.24$ & 0.065 \\
History of pancreatitis (yes/no) & 1.97 & $0.54-7.20$ & 0.304 \\
Diverticulum (yes/no) & 1.08 & $0.49-2.38$ & 0.849 \\
Symptoms at the arriving time (yes/no) & 0.64 & $0.32-1.25$ & 0.191 \\
Purpose for ERCP (treatment/observation) & 1.99 & $0.59-6.73$ & 0.267 \\
Pancreatography (yes/no) & 3.05 & $1.30-7.12$ & $0.010^{*}$ \\
Diclofenac suppository (yes/no) & 1.04 & $0.53-2.03$ & 0.912 \\
Pancreatic stenting (yes/no) & 1.60 & $0.69-3.70$ & 0.271 \\
Time required for ERCP ( $\geq 1$ h/<1 h) & 2.22 & $0.90-5.46$ & 0.082 \\
Start time of ERCP (off hours/regular hours) & 1.30 & $0.66-2.54$ & 0.448 \\
Arrival time of the patient (off hours/regular hours) & 1.02 & $0.43-2.42$ & 0.968 \\
MRCP before ERCP (yes/no) & 1.06 & $0.54-2.07$ & 0.866 \\
\hline
\end{tabular}

$* p<0.05$.

PEP, post-ERCP pancreatitis; BMI, body mass index; ERCP, endoscopic retrograde cholangiopancreatography; MRCP, magnetic resonance cholangiopancreatography.

Table 3. Adjusted ORs for PEP by multivariate analysis

\begin{tabular}{|c|c|c|c|c|c|}
\hline \multirow[t]{2}{*}{ Factors } & \multicolumn{2}{|c|}{ Model 1 (full) ${ }^{\dagger}$} & \multicolumn{3}{|c|}{ Model 2 (stepwise) $)^{\ddagger}$} \\
\hline & adjusted OR & $p$ value & adjusted OR & $95 \% \mathrm{CI}$ & $p$ value \\
\hline Age, years & 2.40 & $0.034^{*}$ & 2.47 & $1.12-5.42$ & $0.024^{*}$ \\
\hline Gender & 5.15 & $0.0002^{*}$ & 4.89 & $2.13-11.20$ & $0.0002 *$ \\
\hline Indications & 1.03 & 0.949 & - & - & - \\
\hline BMI & 2.18 & 0.070 & 2.18 & $0.96-4.94$ & 0.062 \\
\hline History of pancreatitis & 4.30 & 0.070 & 4.63 & $1.04-20.55$ & $0.044^{*}$ \\
\hline Diverticulum & 0.97 & 0.954 & - & - & - \\
\hline Symptoms at the arriving time & 0.55 & 0.188 & - & - & - \\
\hline Purpose for ERCP & 3.30 & 0.101 & 2.76 & $0.74-10.32$ & 0.131 \\
\hline Pancreatography & 2.74 & $0.035^{*}$ & 3.21 & $1.32-7.80$ & $0.010^{*}$ \\
\hline Diclofenac suppository & 0.93 & 0.854 & 0.90 & $0.43-1.90$ & 0.790 \\
\hline Pancreatic stenting & 1.18 & 0.755 & - & - & - \\
\hline Time required for ERCP & 1.64 & 0.407 & - & - & - \\
\hline Beginning time of ERCP & 1.38 & 0.429 & - & - & - \\
\hline Arriving time & 1.49 & 0.447 & - & - & - \\
\hline MRCP before ERCP & 1.14 & 0.750 & 1.14 & $0.52-2.51$ & 0.738 \\
\hline
\end{tabular}

$* p<0.05$.

† Considering all potential risk factors.

‡ Considering age, sex, BMI, history of pancreatitis, purpose of ERCP, pancreatography, diclofenac suppository, and MRCP before ERCP.

PEP, post-ERCP pancreatitis; BMI, body mass index; ERCP, endoscopic retrograde cholangiopancreatography; MRCP, magnetic resonance cholangiopancreatography. 
Table 4. Correlations of pairs of potential risk factors with post-ERCP pancreatitis

\begin{tabular}{lll}
\hline Pairs of potential risk factors & & Correlation \\
\hline $\begin{array}{l}\text { Positive correlation } \\
\text { Symptoms of arrival time }\end{array}$ & 0.34 \\
$\begin{array}{l}\text { Pancreatic stent } \\
\text { Symptoms of arriving time }\end{array}$ & Arrival time of the patient & 0.30 \\
Time required for ERCP & Pancreatography & 0.26 \\
Symptoms of arrival time & Purpose of ERCP & 0.26 \\
Negative correlation & Pancreatic stent & 0.22 \\
MRCP before ERCP & Beginning time of ERCP \\
MRCP before ERCP & Purpose of ERCP & -0.21 \\
\hline \multicolumn{2}{l}{ Only correlation coefficients $|r|$ of $>0.20$ are shown. } & -0.25 \\
ERCP, endoscopic retrograde cholangiopancreatography; MRCP, magnetic resonance cholangiopancreato- \\
graphy.
\end{tabular}

hours. The endoscopic therapeutic approach during off hours might have several risk factors, including lack of enough medical staff members and the arising of emergency situations $[22,23,41,42]$. The present study indicated that off-hours ERCP was not a risk factor for PEP, indicating no reluctance to perform constructive ERCP for emergency cases.

The present single-center retrospective chart review had several limitations: (i) several previous risk factors were not evaluated, including sphincter of Oddi dysfunction, pancreatic sphincterotomy, endoscopic papillary balloon dilatation, and precutting $[10,18]$, (ii) the difficulty for cannulation was evaluated by the time required for ERCP, and (iii) the endoscopists and operative devices varied during the 5-year observation period.

The present study indicated that several risk factors for PEP after ERCP and the performance of ERCP during off hours were not risk factors for PEP. These findings might facilitate active ERCP during emergency situations even in off hours.

\section{Acknowledgment}

The authors thank Angela Morben, DVM, ELS, from Edanz Group (www.edanzediting.com/ac), for editing a draft of this manuscript.

\section{Statement of Ethics}

All patients gave their informed consent, and the research protocol was approved by the institutional review board of Karatsu Red Cross Hospital.

Post-ERCP Pancreatitis

\section{Disclosure Statement}

The authors have no conflicts of interest to disclose.

\section{Funding Sources}

There are no funding sources.

\section{Author Contributions}

T.S.: designed the study, and wrote the initial draft of the manuscript. K.M., T.N., A.T., and K.F.: contributed to analysis and interpretation of data, and assisted in the preparation of the manuscript. All other authors have contributed to data collection and interpretation, and critically reviewed the manuscript. All authors approved the final version of the manuscript, and agree to be accountable for all aspects of the work in ensuring that questions related to the accuracy or integrity of any part of the work are appropriately investigated and resolved.

\section{References}

Digestion 2020;101:557-562

DOI: $10.1159 / 000501309$
1 Takagi K, Ikeda S, Nakagawa Y, Sakaguchi N, Takahashi T, Kumakura K, et al. Retrograde pancreatography and cholangiography by fiber duodenoscope. Gastroenterology. 1970 Sep;59(3):445-52.

2 Minaga K, Kitano M. Recent advances in endoscopic ultrasound-guided biliary drainage. Dig Endosc. 2018 Jan;30(1):38-47.

3 Doshi B, Yasuda I, Ryozawa S, Lee GH. Current endoscopic strategies for managing large bile duct stones. Dig Endosc. 2018 Apr;30(Suppl 1):59-66

4 Ramchandani M, Pal P, Reddy DN. Endoscopic management of acute cholangitis as a result of common bile duct stones. Dig Endosc. 2017 Apr;29(Suppl 2):78-87. 
5 Noda Y, Goshima S, Kojima T, Kawaguchi S, Kawada H, Kawai N, et al. Improved diagnosis of common bile duct stone with single-shot balanced turbo field-echo sequence in MRCP. Abdom Radiol (NY). 2017 Apr;42(4):1183-8.

6 Kamisawa T, Tu Y, Egawa N, Tsuruta K, Okamoto A, Kodama M, et al. Can MRCP replace ERCP for the diagnosis of autoimmune pancreatitis? Abdom Imaging. 2009 May-Jun; 34(3):381-4.

7 Sakai Y, Tsuyuguchi T, Ishihara T, Yukisawa $\mathrm{S}$, Ohara $\mathrm{T}$, Tsuboi $\mathrm{M}$, et al. Is ERCP really necessary in case of suspected spontaneous passage of bile duct stones? World J Gastroenterol. 2009 Jul;15(26):3283-7.

8 Hyodo T, Kumano S, Kushihata F, Okada M, Hirata M, Tsuda T, et al. CT and MR cholangiography: advantages and pitfalls in perioperative evaluation of biliary tree. Br J Radiol. 2012 Jul;85(1015):887-96.

9 Mine T, Morizane T, Kawaguchi Y, Akashi R, Hanada K, Ito T, et al. Clinical practice guideline for post-ERCP pancreatitis. J Gastroenterol. 2017 Sep;52(9):1013-22.

10 Patel BN. Routine MR imaging for pancreas. Magn Reson Imaging Clin N Am. 2018 Aug; 26(3):315-22.

11 Akashi R, Kiyomizu T, Kanda K, Ikuta C, Yamasaki A, Nakahara K, et al. Prospective cohort study on risk factors for aggravation of post-ERCP pancreatitis - the relationship between risk factors for onset and risk factors for aggravation. Gastroenterol Endosc. 2014; 56(9):3324-32.

12 Itoi T, Ryozawa S, Katanuma A, Okabe Y, Kato H, Horaguchi J, et al.; Japan Gastroenterological Endoscopy Society. Japan Gastroenterological Endoscopy Society guidelines for endoscopic papillary large balloon dilation. Dig Endosc. 2018 May;30(3):293-309.

13 Ryozawa S, Itoi $\mathrm{T}$, Katanuma $\mathrm{A}$, Okabe $\mathrm{Y}$, Kato H, Horaguchi J, et al. Japan Gastroenterological Endoscopy Society guidelines for endoscopic sphincterotomy. Dig Endosc. 2018 Mar;30(2):149-73.

14 Ding X, Zhang F, Wang Y. Risk factors for post-ERCP pancreatitis: A systematic review and meta-analysis. Surgeon. 2015 Aug;13(4): 218-29.

15 Hu B, Sun B, Cai Q, Wong Lau JY, Ma S, Itoi $\mathrm{T}$, et al. Asia-Pacific consensus guidelines for endoscopic management of benign biliary strictures. Gastrointest Endosc. 2017 Jul 86(1):44-58.

$16 \mathrm{He}$ QB, Xu T, Wang J, Li YH, Wang L, Zou XP. Risk factors for post-ERCP pancreatitis and hyperamylasemia: A retrospective singlecenter study. J Dig Dis. 2015 Aug; 16(8):4718.

17 Galeazzi M, Mazzola P, Valcarcel B, Bellelli G, Dinelli M, Pasinetti GM, et al. Endoscopic retrograde cholangiopancreatography in the elderly: results of a retrospective study and a geriatricians' point of view. BMC Gastroenterol. 2018 Mar;18(1):38.

18 Morales SJ, Sampath K, Gardner TB. A review of prevention of post-ERCP pancreatitis. Gas- troenterol Hepatol (N Y). 2018 May; 14(5): 286-92.

19 Otsuka T, Kawazoe S, Nakashita S, Kamachi S, Oeda S, Sumida C, et al. Low-dose rectal diclofenac for prevention of post-endoscopic retrograde cholangiopancreatography pancreatitis: a randomized controlled trial. J Gastroenterol. 2012 Aug;47(8):912-7.

20 Katsinelos P, Lazaraki G, Chatzimavroudis G, Terzoudis S, Gatopoulou A, Xanthis A, et al. The impact of age on the incidence and severity of post-endoscopic retrograde cholangiopancreatography pancreatitis. Ann Gastroenterol. 2018 Jan-Feb;31(1):96-101.

21 Masjedizadeh A, Fathizadeh P, Aghamohamadi N. Comparative effectiveness of aggressive intravenous fluid resuscitation with lactated Ringer's solution and rectal indomethacin therapy in the prevention of pancreatitis after endoscopic retrograde cholangiopancreatography: a double blind randomised controlled clinical trial. Prz Gastroenterol. 2017;12(4):271-6.

22 Sugimoto M, Takagi T, Suzuki R, Konno N, Asama $\mathrm{H}$, Watanabe $\mathrm{K}$, et al. Influence of night duty on endoscopic therapy for bile duct stones. World J Gastroenterol. 2016 Nov; 22(42):9387-93.

23 Matsuura S, Sakata Y, Tsuruoka N, Miyahara K, Hara M, Ito Y, et al. Outcomes of patients undergoing endoscopic hemostasis for the upper gastrointestinal bleeding were not influenced by the timing of hospital emergency visits: a situation prevailing in Japan. Digestion. 2018;97(3):260-6.

24 Cotton PB, Lehman G, Vennes J, Geenen JE, Russell RC, Meyers WC, et al. Endoscopic sphincterotomy complications and their management: an attempt at consensus. Gastrointest Endosc. 1991 May-Jun;37(3):383-93.

25 Yokoe M, Takada T, Mayumi T, Yoshida M, Isaji S, Wada K, et al. Japanese guidelines for the management of acute pancreatitis: Japanese Guidelines 2015. J Hepatobiliary Pancreat Sci. 2015 Jun;22(6):405-32.

26 Laugier R, Bernard JP, Berthezene P, Dupuy $P$. Changes in pancreatic exocrine secretion with age: pancreatic exocrine secretion does decrease in the elderly. Digestion. 1991;50(34):202-11.

27 Loperfido S, Angelini G, Benedetti G, Chilovi F, Costan F, De Berardinis F, et al. Major early complications from diagnostic and therapeutic ERCP: a prospective multicenter study. Gastrointest Endosc. 1998 Jul;48(1):1-10.

28 Li GZ, Wang F, Fang J, Zha HL, Zhao Q. Risk factors for post-endoscopic retrograde cholangiopancreatography pancreatitis: evidence from 1786 Cases. Med Sci Monit. 2018 Nov; 24:8544-52.

29 Masci E, Mariani A, Curioni S, Testoni PA. Risk factors for pancreatitis following endoscopic retrograde cholangiopancreatography: a meta-analysis. Endoscopy. 2003 Oct;35(10): $830-4$.

30 Chen JJ, Wang XM, Liu XQ, Li W, Dong M, Suo ZW, et al. Risk factors for post-ERCP pancreatitis: a systematic review of clinical tri- als with a large sample size in the past 10 years Eur J Med Res. 2014 May;19(1):26.

31 Masci E, Toti G, Mariani A, Curioni S, Lomazzi A, Dinelli M, et al. Complications of diagnostic and therapeutic ERCP: a prospective multicenter study. Am J Gastroenterol. 2001 Feb;96(2):417-23.

32 Freeman ML, DiSario JA, Nelson DB, Fennerty MB, Lee JG, Bjorkman DJ, et al. Risk factors for post-ERCP pancreatitis: a prospective, multicenter study. Gastrointest Endosc. 2001 Oct;54(4):425-34.

33 Christensen M, Matzen P, Schulze S, Rosenberg J. Complications of ERCP: a prospective study. Gastrointest Endosc. 2004 Nov;60(5): 721-31.

34 Zhang C, Yang YL, Ma YF, Zhang HW, Li JY, Lin MJ, et al. The modified pancreatic stent system for prevention of post-ERCP pancreatitis: a case-control study. BMC Gastroenterol. 2017 Oct;17(1):108.

35 Sigounas DE, Christodoulou DK, Tatsioni A, Katsanos KH, Baltayiannis G, Kappas A, et al. Pancreatitis potentially associated drugs as a risk factor for post-endoscopic retrograde cholangiopancreatography pancreatitis: a prospective cohort study. Pancreas. 2013 May;42(4):601-6.

36 Wang J, Shen Y, Zhong Z, Wu S, Zheng L. Risk factors for post-endoscopic retrograde cholangiopancreatography (ERCP) pancreatitis and the effect of octreotide combined with nonsteroidal anti-inflammatory drugs on preventing its occurrence. Med Sci Monit. 2018 Dec;24:8964-9.

37 Elmunzer BJ, Waljee AK, Elta GH, Taylor JR, Fehmi SM, Higgins PD. A meta-analysis of rectal NSAIDs in the prevention of post-ERCP pancreatitis. Gut. 2008 Sep;57(9):1262-7.

38 Okuno M, Shiroko J, Taguchi D, Yamaguchi $\mathrm{K}$, Takada J, Imai S, et al. The effectiveness of the rectal administration of low-dose diclofenac for the prevention of post-endoscopic retrograde cholangiopancreatography pancreatitis. Intern Med. 2018 Aug;57(16):2289-94.

39 Sofuni A, Maguchi H, Mukai T, Kawakami H, Irisawa A, Kubota K, et al. Endoscopic pancreatic duct stents reduce the incidence of post-endoscopic retrograde cholangiopancreatography pancreatitis in high-risk patients. Clin Gastroenterol Hepatol. 2011 Oct; 9(10):851-8.

40 Hakuta R, Hamada T, Nakai Y, Isayama $H$, Kogure H, Takahara N, et al. Early pancreatic stent placement in wire-guided biliary cannulation: a multicenter retrospective study. J Gastroenterol Hepatol. 2019 Jun;34(6):1116-22.

41 Tohda G, Ohtani M, Dochin M. Efficacy and safety of emergency endoscopic retrograde cholangiopancreatography for acute cholangitis in the elderly. World J Gastroenterol. 2016 Oct;22(37):8382-8

42 Hui CK, Liu CL, Lai KC, Chan SC, Hu WH, Wong WM, et al. Outcome of emergency ERCP for acute cholangitis in patients 90 years of age and older. Aliment Pharmacol Ther. 2004 Jun;19(11):1153-8. 